\title{
Postpartum Depression Experience Among Jordanian Mother With Hospitalized Infant in Neonatal Intensive Care Unit: Incidence and Associated Factors
}

\author{
Roqia Maabreh $^{1} \&$ Dua'a Al Maghaireh ${ }^{1}$ \\ ${ }^{1}$ Assistant Professor, Irbid National University, Irbid, Jordan \\ Correspondence: Dua'a F. Al Maghaireh, Assistant Professor, Irbid National University, Irbid, Jordan. E-mail: \\ dfm_2013@yahoo.com
}

Received: January 7, 2019 Accepted: March 12, 2019 Online Published: April 3, 2019

doi:10.5539/gjhs.v11n5p21 URL: https://doi.org/10.5539/gjhs.v11n5p21

\begin{abstract}
Postpartum depression (PPD) is a global mental health problem that affects about $13 \%$ to $19 \%$ of mothers who have recent given birth. This problem increases if the infant is admitted to the intensive care unit (NICU). The aims of this study were to examine the prevalence and risk factors of postpartum depression among mothers with hospitalized infant on NICU and to explore mothers experience after admitting their infants to the NICU. A varied methods research design were undertaken in two hospitals in Jordan. The Edinburgh Postpartum Depression Scale (EPDS) was used to survey 188 Jordanian mothers with infants in the NICU, it deals with semi-structured in-depth interviews to identify the themes that characterize mothers PPD experience in the NICU. The quantitative results of this study showed that the mothers with hospitalized infant in NICU experienced high level of PPD with the mean score was $20.81(\mathrm{SD}=4.92)$. With regard to qualitative results, two major themes with nine subthemes : the first one is Postpartum Depression Experience and the second theme was sources that influence postpartum depression.

In conclusion, the mothers with hospitalized infant in NICU experience PPD. the PPD mothers experience many manifestations during this situation such as : shock, surprise, crying, Anhedonia,hopelessness and thinking about harming themselves or their babies after admission of their infants to the NICU, Also there are many sources that influence postpartum depression such as baby gender, lack of knowledge, social support, mother role, mother infant attachment, stigma and shame.
\end{abstract}

Keywords: postpartum depression, mothers, NICU, experience

\section{Introduction}

Postpartum depression (PPD) is a global mental health problem that affects about $13 \%$ to $19 \%$ of mothers who have recent given birth. This problem increases if the infant is admitted to the intensive care unit (NICU), a recent statistic published by (Rahal, 2018) found that PPD may affect as many as 70 percent of mothers whose infant is admitted to NICU in the following of their births.

PPD is characterized as a persistent low mood, feelings of sadness, hopelessness, or/and worthlessness. There are many factors that increase the incidence of postpartum depression. Most studies have found a direct correlation between born premature infant and admitted to NICU and increase the incidence of postpartum depression (Alaradi, 2014; Busse et al., 2013; Dellenmark-Blom \& Wigert, 2014; Mohammad, 2008).

A cross-sectional comparative study was carried out by Shelton et al. (2014) to compare depression symptoms among mothers after hospitalizing their infants to NICU. The study was conducted on a convenient sample of 55 first-time mothers during the second week after admission of their infants to NICU. Results showed that approximately $62 \%$ of mothers report high depression levels. They concluded that mothers with hospitalized infants in NICU suffer from depression which will effect on their everday life activties (Shelton et al., 2014).

In addition, Yurdakul et al. (2009) conducted a case control study among two groups. The first is the NICU group of mothers with hospitalized infants in NICU, and the second is a control group of mothers with healthy full-term infants. The purpose of this study was to determine depression symptoms, as well as attachment style. The researchers used the Edinburgh Postpartum Depression Scale (EPDS). Results showed that depression was 
significantly higher in the NICU group $\mathrm{M}(\mathrm{SD})=9.6$ (5.6) than in the control group $\mathrm{M}(\mathrm{SD})=4.9$ (4.9).

Postpartum depression is a very important issue. Unaddressed, it may be harmful to the family system by influencing the behaviors and cognitions displayed by mothers to their children (Roy et al., 2014). A premature birth with the infant hospitalized in NICU has been associated with psychological problems among mothers. High prevalence of postpartum depression among mothers of hospitalized infants in NICU compared to mothers with healthy full-term infants may be attributed to separation from the infant. Early separation between mothers and infants, that is, within the first 24 hours after birth, contributes to an increase in postpartum (Flacking et al., 2012). Studies show that these issues continue beyond the NICU hospitalization period after discharge from NICU, it was found that mothers elevated depression level and infants' low responsiveness negatively impact development of a relationship with their premature infants (Korja, 2009; Flacking et al., 2012). A few studies in Jordan determined the postpartum depression by difference associated factors such as (Mother Infant Contacts, Breastfeeding and infant characteristic). The present study aims to examine the prevalence and risk factors of postpartum depression among mothers with hospitalized infant on NICU and to explore mothers experience after admitting their infants to the NICU.

\section{Methodology}

\subsection{Design}

An Explanatory mixed methods design was used to conduct this study. This explanatory study consists of two phases: quantitative design, followed by qualitative design. The quantitative research design used a descriptive, cross-sectional survey design. A quantitative approach was chosen because it allows the researcher to describe and examine the relationship among the variables (Creswell, 2013). A cross-sectional survey was selected, as self-reported data facilitates collection at one point in time. Mothers who participated in the survey and experienced high postpartum depression level were invited to attend a face-to-face interview to explore their experiences.

\subsection{Participants}

Convenience sampling technique was used to recruit 188 the mothers chosen for quantitative design and A non-probabilistic, purposive sampling method was chosen to recruit participants who met the qualitative sampling criteria.

\section{- Quantitative Sampling Technique}

Convenience sampling technique was used to recruit the mothers chosen for quantitative design. The inclusion criteria includes: Jordanian mothers, who speak Arabic language, consent to participate in the study; they have hospitalized infants in the NICU and they are product of a singleton pregnancy. The exclusion criteria are non-Jordanian mothers, mothers with critically-ill infants in the NICU, mothers who have lost their babies after NICU admission, mothers who have an admission to NICU experience, and mothers whose hospitalized infant is the product of a twin pregnancy.

Sample size is calculated based on the estimation population proportion formula (Scheaffer, Mendenhall III, Ott, \& Gerow, 2011). The purpose of drawing a sample is to make inferences about the population from the information collected about the sample. Scheaffer et al. (2011) clarified that the sample size of a survey is usually determined by estimating the proportion of the population.

In this study, the population is 3171 infants admitted to NICU per year. This is considered large population; therefore the formula below, with reference to Scheaffter et al. (2011), was used to calculate the sample size.

\section{- Calculating Sample Size}

$$
\begin{aligned}
& \mathbf{D}=\frac{\mathbf{B}^{2}}{\mathbf{4}}=\frac{(0.05)^{2}}{4}=0.625 \times 10^{-3} \\
& \mathbf{n}=\frac{\mathbf{N} \boldsymbol{p q}}{(\mathbf{N}-\mathbf{1}) \mathbf{D}+\boldsymbol{p q}}=\frac{3171 \times 0.5 \times 0.5}{3170 \times\left(0.625 \times 10^{-3}\right)+0.5 \times 0.5}=188.161994
\end{aligned}
$$

Hence, the recommended sample size for this study is 188 .

\section{- Qualitative Sampling Technique}

A non-probabilistic, purposive sampling method was used to recruit 18 mothers who met the qualitative sampling criteria. The study included mothers who had their first experience with NICU admission and didn't lose their babies after NICU admission. 
The aim of the qualitative study is not to obtain a statistically representative sample size for generalizability of the findings (Myles, 2015). However, it was emphasized by Baker, Edwards (2012), Guest, Bunce, and Johnson (2006) that sample size should be adequate to allow in-depth analysis and provide deeper understanding of the topic.

The qualitative sample size is determined until the data reached a saturation point (Baker \& Edwards, 2012; Guest et al., 2006). Thus, no sample size calculation is performed.

\subsection{Instruments}

\section{Infant Demographic Data Questionnaire}

Demographic data about infants were collected from the electronic medical system. Information obtained includes infants name, gender, birth weight, gestational age, and medical diagnosis.

Information on infant characteristics was sorted into three classes according to the severity of the infants' medical conditions because all hospitals in Jordan follow this classification (Kliegman, Stanton, Geme, Schor, and Behrman, 2015). The "severe" class consists of infants who are fasting, depending on total parental nutrition (TPN) and intravenous fluid, or depending completely on mechanical ventilators; the "moderate" class consists of infants who need oxygen supplements by incubator or nasal cannula, phototherapy, nasogastric tube feeding, or blood transfusion; and the "mild" class consists of infants who are admitted to the NICU for feeding and weight gain (Kliegman et al., 2015)

\section{The Edinburgh Postpartum Depression Scale (EPDS)}

The EPDS was developed for screening postpartum women up to 8 week postpartum. The EPDS consists of 10 questions. The test can usually be completed in less than 5 minutes. Responses are scored $0,1,2$, or 3 according to increase severity of the symptom. Items marked with an asterisk $(*)$ are reverse scored (i.e., $3,2,1$, and 0 ). The total score is determined by adding the scores for each of the 10 items together. A rating of 0 means that the experience did not cause any depression for the mother; whereas a rating of 3 means that the experience upset the mothers and caused a great deal of depression. The scales were translated into Arabic version, then tested and found acceptable in Jordan, where the alpha coefficients were $>.70$ for all scales. The internal consistencies for the entire scales of the Arabic version were.72 and.95.

\subsection{Study Setting}

This study was conducted in two government teaching hospitals in Jordan; they were selected because they are the biggest teaching hospitals. Hospital A is located in Amman, with a capacity of 1,100 beds and NICU capacity of 65 beds. Hospital B is located in Irbid, with a capacity of 140 beds and NICU capacity of 30 beds. All NICUs are Level III NICUs (Provide care for infants with less than 32 gestational weeks, infants born with critical conditions at all gestational ages, and infants who need to gain weight. This unit consists of advanced respiratory technological support, providing care for healthy full-term infants who need continuous monitoring and phototherapy; provide basic level of care for infants requiring short-term intensive care, tube feeding, and continuous positive airway pressure (CPAP)). Both hospitals provide similar medical services: advanced respiratory support and mechanical ventilator support.

\subsection{Ethical Consideration}

The study was approved by the Ethical Committee of the Medical Research Ethics Committee, Ministry of Health, Jordan (No. Development/plans/74321), conducting the study in all public hospitals in Jordan. Two of the biggest hospitals in Jordan were selected because these hospitals offer NICU services. Mothers were assured of the confidentiality of the study. Anonymity was established through the use of codes, rather than mothers and infants' names. Informed written consent was obtained from participants after clear and detailed explanations about the objectives of the study.

\subsection{Data Collection}

Data collection was conducted in two phases: quantitative phase, and qualitative data phase. The former includes the administration of the EPDS instrument to a convenience sample, whereas the latter includes semi-structured in-depth interviews with selected mothers.

On the first day of hospital admission, the infant's files and electric medical system records were checked, to identify those who met the inclusion criteria. The home address and phone number of mothers were recorded. The researcher interviewed mothers in the small room beside NICU to provide privacy, and then distributed questionnaires to 188 mothers. The questionnaires were then collected from each mother before they leave the unit. 
In the second phase, qualitative semi-structured in-depth interviews were used to identify the themes that characterize mothers experience in the NICU. The researcher prepared two questions (How did you feel when your baby was admitted to the NICU, why did you feel depressed when your baby was admitted to the NICU?), which were reviewed by four nursing professionals (A, B, C). Professional A is an Assistant professor in nursing college at University of Jordan; Professional B is a lecturer in the Department of Nursing Sciences at Jordan University of Science and Technology and Professional $\mathrm{C}$ is an associate professor in the Faculty of Nursing at Irbid National University.

Mothers were interviewed in a closed room to avoid interruptions and ensure privacy during the interview. First of all, the aim and the process of interview were identified by the researcher. After that informed consent was obtained by the researcher and assured mothers that all data would be confidential and the mothers were informed that they could withdraw at any time. During the interview, the researcher asked mothers two open-ended questions to encourage mothers to explain their ideas and feelings. The researcher recorded the interview by smart phone after written permission obtained by mothers to record the interview. The researcher recorded the interview because taking comprehensive notes in real-time would have resulted in decreased eye contact and reduced listening capacity throughout the interview, also he/she may lose a lot of important information.

After the interview, the researcher uploaded all the audio recording data into a computer by connecting the mobile phone via USB port. The researcher made many copies of the audio files and stored them in many different data storage devices (e.g. a computer, USB drive, Google Drive and external hard drive) to prevent data loss.

\subsection{Normality Test for the Data Distribution}

A Kolmogorov-Smirnov test $(\mathrm{p}<.5)$ (Razail \& Wah, 2011) and a visual inspection of the histograms, normal Q-Q plots, and box plots show that depression level scores do not follow a normal distribution, with space a askewness of $-0.873(\mathrm{SE}=.125)$ and kurtosis of.023 ( $\mathrm{SE}=.262)$ (Razail \& Wah, 2011). Thus, nonparametric tests are used.

\subsection{Planned Analysis}

Data analysis was conducted separately for the quantitative and qualitative data sets. The quantitative results were analyzed using descriptive and inferential statistics, the Mann-Whitney U test, the Kruskal-Wallis test, Spearman's rank correlation coefficient, and Smart PLS. The qualitative results, on the other hand, required transcription, translation, coding, and thematic analysis.

\section{Planned Statistical Analysis of the Quantitative Design}

Statistical Package for Social Sciences (SPSS) Graduate Pack 21.0 was used to analyze relationships among the variables and answer the research questions. Descriptive and inferential statistics were used to describe the sociodemographic data of the sample. The researcher computed the total score for EPDS, and then compared the means and calculated the mean and standard deviation to each item. The Mann-Whitney U test was used to compare differences in overall depression for infant characteristics such as gender. The Kruskal-Wallis test was employed to compare the differences in overall depression levels and impact of depression for infant characteristics, the same tests were used for gestational age, birth weight, and severity of medical condition.

The researcher followed Mayer (2015) steps of qualitative analysis steps to analyze the data of this study (Table 1). After each interview, audio recording files from the interview were uploaded from a mobile smart Phone into a computer, and stored in a folder. Then, through repeating recordings; the researcher transcribed the audio recordings verbatim into textual data. The researcher took notes of mother's response, attitude and behavior during the interview, to avoid loss of details due to forgetfulness. Interview transcripts and written field notes were saved as Word documents. After that, two translators translated the data from Arabic into English. Transcripts were read and reread for immersion. Following that, the researcher reflected on the overall meaning about what the mothers said, and assessed the general impression of credibility and depth of the information. After initial reading to acquire a general, preliminary sense of the content of the textual data, thorough reviewing data was carried out, beginning with the interview transcripts. Textual data was read, sentence-by-sentence and in details, as part of the comprehensive data treatment described by Silverman (2005). While reading through the data source, the researcher was mindful to ask related questions about the data such as, "What is this person trying to say? Which experience is represented here?" The researcher strove to be alert to participants' statements and meaningful expressions of perspectives, views, or experiences. The preliminary coding process was done manually, with attempts to interpret interview responses. The researcher made annotations of thoughts that arose regarding to particular data segments. The coding process analysis was assisted by two researchers; segments of textual data were assigned different coding labels and negative cases were excluded. Data analysis was done manually by three professionals to identify recurrent themes. Theme refers to "topic or information with similar content". All 
information that had been coded from a single source (interview transcripts) were inspected and compared with other coded information within the data sources. During the coding process, themes were identified and analyzed from individual cases and across different cases.

Each theme was identified and described. The researchers discussed information regarding each theme and rationalized it. Parental experiences, as gathered from the interview transcripts, were categorized into relevant themes. Direct quotes served as evidence for each theme.

Table 1. Steps of qualitative analysis

\section{Qualitative Data Collection}

Step 1: Preparing, organizing and translating of data analysis

Step 2: Reading through all the data

Step 3: Reading and understanding interviews and coding process

Step 4: Forming themes and subthemes using the coding process

Step 5: Representing and describing themes

Step 6: Reviewing and refining the themes by experts

Step 7: Interpretation

\section{Results}

\subsection{Quantitative Results}

A total of 188 Jordanian mothers with infants admitted to the NICU participated in this study. Mother's ages ranged between 17 and 55 years, and the mean age for mothers was $32.93 \pm 7.077$. All mothers were married Muslims ones. More than half of the participants $(54.2 \%, \mathrm{n}=105)$ had bachelor degree, $18.9 \%(\mathrm{n}=38)$ had diplomas, 9.6\% $(\mathrm{n}=22)$ had postgraduate degrees, $16.1 \%(\mathrm{n}=18)$ had secondary education, and $1.2 \%(\mathrm{n}=5)$ had primary education. The result showed that the majority $(\mathrm{n}=104)$ of the mothers had a high income more than $\$ 714$; on the other hand $(\mathrm{n}=4)$ mothers who had a low income equal or less than $\$ 357$.

\subsection{Infants' Demographic Data}

In this study, there was the total of 188 infants admitted to NICUs across two hospitals. 106 infants were male $(54.9 \%)$ and $82(45.1 \%)$ were female. More than half of the sample $(58.7 \%, \mathrm{n}=111)$ consisted of premature infants aged from 28 to 36 weeks, $35.5 \%(n=66)$ were full-term babies aged from 37 to 42 weeks, and $5.8 \%(n=11)$ were very premature infants aged less than 28 weeks. Other infant characteristics recorded are birth weight and classification of medical condition. Table 2 represents the demographic characteristics of infants.

Table 2. Infants' demographic data $(\mathrm{N}=188)$

\section{Variables}

\section{Infant Gestational Age}

Very premature $(<28$ weeks $)$

Premature (28-36 weeks)

Full-term (37-42 weeks)

\section{Mothers Characteristics}

$\mathrm{N}=188(\%)$

\section{Infant Gender}

Male

$106(54.9 \%)$

Female

$$
\begin{aligned}
& 11(5.8 \%) \\
& 111(58.7 \%) \\
& 66(35.5 \%)
\end{aligned}
$$

$106(54.9 \%)$
$82(45.1 \%)$




\section{Infant Birth Weight}

$\begin{array}{ll}\text { Very low }(<1500 \text { grams }) & 71(37.4 \%) \\ \text { Low }(1500-2500 \text { grams) } & 96(47.5 \%) \\ \text { Normal }(>2500 \text { grams) } & 21(15.1 \%)\end{array}$

\section{Classification of Medical Condition*}

Mild

$36(19.2 \%)$

Moderate

$53(28.7 \%)$

Severe

$99(52.1 \%)$

\subsection{Perception of Post Partum Depression}

The perception of post partum depression among the mothers was measured using Edinburgh Postpartum Depression Scale. As shown in table 1, descriptive analysis showed that the mean score was 20.81 with SD $=4.92$, with the lowest score was 0 and the highest score was 30.00. The descriptive analysis of perceived stress item analysis (see Table 1) showed that the highest mean score $(\mathrm{M}(\mathrm{SD})=2.26(1.15)$ was reported for item 8 "I have felt sad or miserable" followed by item $4 \mathrm{M}(\mathrm{SD})=2.25(1.17)$ "I have been anxious or worried for no good reason". The lowest mean score $\mathrm{M}(\mathrm{SD})=1.72$ (1.31) was reported for item 1 "I have been able to laugh and see the funny side of things".

Table 1. Total item mean and standard deviation of The Edinburgh Postpartum Depression Scale (EPDS)

\begin{tabular}{cll}
\hline The Edinburgh Postpartum Depression Scale & M (SD) \\
\hline 1. I have been able to laugh and see the funny side of things & $1.72(1.31)$ \\
2. I have looked at things with enjoyment & $1.75(1.19)$ \\
3. I have blamed myself unnecessarily when things went wrong & $2.40(1.29)$ \\
4. I have been anxious or worried for no good reason & $2.25(1.17)$ \\
5. I have felt scared or panicky for no very good reason & $2.24(1.20)$ \\
6. Things have been getting on top of me & $1.86(1.18)$ \\
7. I have been so unhappy that I have had difficulty sleeping & $2.08(1.20)$ \\
8. I have felt sad or miserable & $2.26(1.15)$ \\
9. I have been so unhappy that I have been crying & $2.22(1.25)$ \\
10. The thought of harming myself has occurred to me & $2.03(1.36)$ \\
\hline Total Score & $20.81(4.92)$ \\
\hline
\end{tabular}

\subsection{The Influence of Infant Characteristics on Depression}

The infant's gender, gestational age, birth weight, and medical condition were examined for impact on depression levels. Based on the Mann-Whitney U test of $489.9(p=.001)$, the mean rank for depression among mothers with male infants $(\mathrm{n}=106)$ was 89.14 , whereas the mean rank for depression among mothers with female infants $(\mathrm{n}=$ 82) was 100.39. Thus, gender is a statistically significant contributing infant characteristic to postpartum depression. The mother who born a girl gender infant have postpartum depression compared with a mother who born a boy gender.

Differences in depression related to gestational age $\left(\chi^{2}=25.85, d f=2, p=.001\right)$ were found to be significant. Mothers of infants with lower gestational age $(<28$ weeks $)(\mathrm{M}=111.23)$ have higher depression levels than mothers of infants with higher gestational age $(\mathrm{M}=64.68)$. Birth weight has a significant impact on depression in mothers $\left(\chi^{2}=30.108, d f=2, p=.001\right)$, whereby mothers of infants with very low birth weight of less than 1500 grams $(M=106.66)$ experience higher levels of anxiety than mothers of infants with low $(M=60.90)$ or normal $(M$ $=86.40$ ) birth weight. The severity of an infant's medical condition is determined by the gestational age, birth weight, medical complications, and dependency of technology to recover or survive. This is divided into three 
classes: mild, moderate, and severe, and found to be significant related to depression $\left(\chi^{2}=49.226, d f=2, p=.001\right)$. Mothers of infants with severe conditions $(n=99, M=116.94)$ experience more depression than those with moderate $(n=53, M=84.99)$ or mild $(n=36, M=43.87)$ infants (Table 2$)$.

Table 2. The influence of infant characteristics on postpartum depression

\begin{tabular}{|c|c|c|c|c|c|}
\hline Infant Characteristics & $\mathbf{N}$ & Mean Rank & $\chi^{2}$ & $p$-value & $d f$ \\
\hline \multicolumn{6}{|l|}{ Gestational Age (weeks) } \\
\hline Very premature $(<28)$ & 11 & 111.23 & \multirow{3}{*}{25.85} & \multirow{3}{*}{.001} & \multirow{3}{*}{2} \\
\hline Premature (28-36) & 111 & 71.33 & & & \\
\hline Full-term (37-42) & 66 & 64.68 & & & \\
\hline \multicolumn{6}{|l|}{ Birth Weight (grams) } \\
\hline Very low $(<1500)$ & 71 & 106.66 & \multirow{3}{*}{30.108} & \multirow{3}{*}{.001} & \multirow{3}{*}{2} \\
\hline Low (1500-2500) & 96 & 60.90 & & & \\
\hline Normal $>2500$ & 21 & 86.40 & & & \\
\hline \multicolumn{6}{|l|}{ Medical Condition } \\
\hline Mild & 36 & 43.87 & \multirow{3}{*}{49.226} & \multirow{3}{*}{.001} & \multirow{3}{*}{2} \\
\hline Moderate & 53 & 84.99 & & & \\
\hline Severe & 99 & 116.94 & & & \\
\hline
\end{tabular}

\subsection{Qualitative Results}

The demographic characteristics of 18 mothers are presented in Tables 2 to provide context and facilitate deeper understanding of mother postpartum depression experience.

Table 3. Mother characteristics

\begin{tabular}{ll}
\hline Variable & Mean Average \\
\hline Age (Year) & 29 \\
\hline Hospital & N (18 mothers) \\
$\quad$ Hospital A & 10 \\
Hospital B & 8 \\
\hline Education Level & \\
Elementary & 1 \\
Secondary & 4 \\
Diploma & 6 \\
Bachelor & 5 \\
Postgraduate & 2 \\
\hline Financial Status (JD) & \\
$\leq 250$ & 5 \\
$251-500$ & 8 \\
$>500$ & 5 \\
\hline
\end{tabular}




\begin{tabular}{ll}
\hline Distance between Residence and Hospital $(\mathbf{k m})$ & \\
$\leq 15$ & 10 \\
$16-25$ & 5 \\
$26-35$ & 2 \\
$\geq 36$ & 1 \\
\hline First Baby & 9 \\
Yes & 9 \\
No & 7 \\
\hline Type of Delivery & 11 \\
Caesarian Section (CS) & \\
Normal Vaginal Delivery (NVD) &
\end{tabular}

Thematic analysis of textual data from interview transcripts and field notes yielded two major themes with nine subthemes, as presented in Table 4.

Table 4.

\section{Themes}

Postpartum Depression Experience

- $\quad$ Shock

- Crying

- Anhedonia and Hopelessness

- Thinking about harming herself or her baby

Sources that influence postpartum depression

- Baby Gender

- Lack of knowledge

- Social Support

- Mother Role and Mother Infant Attachment

- Stigma and shame

\subsection{Post-Depression Experience}

This section provides details of mother's experience of many depression symptoms with themselves and their family members, as a direct result of having a baby admitted to the NICU. These various intense emotions are divided into the subthemes of:

\subsubsection{Shock}

All mothers were inundated with many depression symptoms such as shock, crying, losing interest in activities and thinking about harming herself or her baby. All mothers had not prepared themselves to face this problem due to normal pregnancy period.

\section{One of the mothers ${ }^{\mathrm{A}}$ recounted her experience as below:}

"I was shocked. I do not believe it, why this happened to me, the world is dark in my eye, I couldn't stand on my feet when the doctor told me your baby need admition to NICU, this is a crisis for me"

\subsubsection{Crying}

For most of the mothers, the initial response after they were informed of their baby's admission to the NICU was a crying. This is a common expression among mothers as they feared their babies might be perceived as having some genetic disorder. 
Mother ${ }^{\mathrm{B}}$ expressed their response of crying as below:

"When my baby is admitted to NICU, the initial response is crying, I can't do anything except continues cryin ".

3.6.3 Anhedonia and Hopelessness

For a few mothers, the period of NICU admission was struggling feelings of Anhedonia and hopelessness. For others, the hopelessness of the situation caused begging feelings of hatred towards themselves, the babies, and their lives. Illustrative quotes for mother ${ }^{\mathrm{C}}$ as below:

"I hate my life when my daughter is admitted to NICU; I feel hopeless because I can't help my daughter... I hate my life.... my family.... My daughter.... and even myself...... I lose the interest in anything... I hate everything; I don't have a pleasure to do anything".

3.6.4 Thinking About Harming Herself or Her Baby

At the same time, several mothers expressed irrational feelings of hatred towards themselves, their babies, or their lives. There are a number of mothers who wanted to harm their infants, neglected them, didn't care them, also they neglected and tried to harm them. Illustrative quotes for mother ${ }^{\mathbf{D}}$ as below:

"I hate myself...... I hate my son.... I don't want to change diaper.... feed.... change the clothes for him.... I don't want him because he is sick and unhealthy baby.....

\subsection{Sources That Influence Postpartum Depression}

\subsubsection{Baby Gender}

Most of mothers depressed because the gender of their baby is a girl.. Illustrative quotes for mother ${ }^{\mathrm{f}}$ as below:

"I hate my baby... I want to kill her because it is a girl.... I have six girls... I hate myself because I can't bear a boy... I have just born a girl.... God please end my life I do not love my life.... I hate being alive."

\subsubsection{Lack of Knowledge}

Lack of knowledge is an important reason for depressed feeling because the mothers have many questions regarding infant health status, recovery progress, medications, medical interventions, medical jargon, or how to care for the infant in the future. Mothers had many questions about the duration of hospitalization, appropriate treatments and interventions, and the impact of NICU admission on the physical and mental development of their infants.

It is known that the parents have misconceptions about premature babies or babies are admitted to the NICU, mistakenly believed that their babies are abnormal or different from other infants. In addition, mothers fear is aggravated by the medical jargon used among health care professionals; they assume the worst about their infants' health status because they do not fully understand the medical terms used.

Mother ${ }^{\mathrm{I}}$ expressed their feelings as below:

"I was depressed when I heard a doctor using many medical terms... I worried about my baby... I think the doctor used Medical terminology and talked to the nurse in English because he didn't want me to understand the health status of my baby...., the nurse refused to tell me any information about the status of my baby"

\subsubsection{Social Support}

A few mothers can't find any support from their friends or families, they feel lonely, they can't explain their feelings to any one which increased the symptoms of postpartum depression.

Mother ${ }^{\mathrm{h}}$ expressed their feelings as below:

"I can't express my emotions to anyone.... All people around me are busy.... I need someone to tell him or her about my feelings.... I need to talk but I didn't find anyone".

\subsubsection{Mother Role and Mother Infant Attachment}

Infant hospitalization in the NICU holds many stressors for mothers, many of them are evoked by the crisis of mother-infant separation early in the infant life. Many mothers, separated from their infants, reported an interruption in the development of a healthy mother-infant relationship. Normal transition to motherhood is delayed, so mother cannot carry out their role of mothering. The primary cause of depressed feeling for mother is the inability to carry out their roles and responsibilities as mothers, which is to feed, clothe, and hold their infants. Mothers are unable to breastfeed their babies. Rather than bringing their infants home, they are separated from their infants by a pane of glass, from where physical touch and personal interaction is difficult, if it is not impossible. Illustrative quotes for mother ${ }^{\mathrm{g}}$ as below: 
"This is a first baby for me.... I can't do my mother role... I miss to breast him.... change his clothes...........look to his small eyes.... Carry him with my arms"

\subsubsection{Stigma \& Shame}

The majority of the mothers. Especially, who born a girl infant, have common feeling is shame and stigma from admission their baby to NICU and they feared their babies might be perceived some genetic disorder.

Mothers expressed their feelings of shame and stigma as below:

"I feel shame when my family or any person asked me about my daughter... I am ashamed when telling her/him "My daughter has been admitted to the NICU after delivery", I am worried about her future because people may say this family has a genetic disorder and nobody may want to marry her or any girl from my family.

\section{Discussion}

In this mixed methods design study, qualitative results provide useful information that explain and support quantitative results. The quantitative results of this study showed that the mothers with hospitalized infant in NICU experienced high level of PPD with the mean score was $20.81(\mathrm{SD}=4.92)$. The result of this study was similar to Davis et al, (2003) \& Lefkowitz, Baxt, \& Evans, (2010) who found that the mother experienced high prevelance of postpartum depression when their infant hospitalized in NICU with mean score 22.91 and 21.09 respectively.

According to our knowledge, there are no mixed design studies which support our findings, there are no studies comparing between the influence of mothers and infant characteristics on postpartum depression. The results of this study found that the gender of the infant results in a significant difference in postpartum depression; mothers with female infants experience higher scores of postpartum depression than those with male infants. Infant gestational age of less than 28 weeks resulted in higher depression scores in mothers. Finally, mothers of infants with severe medical conditions experienced higher depression than mothers of infants with moderate or mild conditions.

To explain the quantitative results of the study, the qualitative results showed that mothers who experience postpartum depression suffered from many emotional problems such a shock, surprise, crying, anhedonia and hopelessness and thinking about harming herself or her baby after the admission of their infants to the NICU. Mother felt shocked and surprised when their infants needed admission to the NICU. They described this situation as a crisis; most of them had not been mentally prepared to face this challenge. Many mothers expressed that their pregnancy experience had been normal and they were expecting a normal transition into motherhood, as well as a normal first encounter with their infants.

The infant hospitalization in the NICU put mother in a complicated emotional situation which results in shock and thinking to harm herself or her baby. Furthermore, the hospitalization of an infant within the first two weeks of birth, either directly after birth causes a number of problems for mothers; many are evoked by the experience of separation or interrupted mother-infant attachment (Eapen et al., 2014, Maghaireh et al, 2017, Arnold et al., 2013, Heidari et al., 2012, 2013; Heinemann et al., 2013; Whittingham et al., 2014).

Moreover, a hospitalized infant takes a toll on the mother's emotions and peace of mind; they descend into postpartum depression such as despair and disappointment. Heidari et al. (2013) found that mothers who diagnosed postpartum depression after hospitalizing their infant to NICU experience many symptoms like continuous crying, anhedonia ( don't feel pleasure to anything ), hopelessness and thinking about harming herself or her baby. The negative feelings of PPD were the main reason for delaying the mothers' normal transition to motherhood and carrying out their mother's roles. They feel like an outsider because of the NICU environment and not knowing what to do in the unfamiliar situation (Heidari et al., 2012, 2013; Eapen et al., 2014, Maghaireh et al, 2017). The sources that increased the incidence of PPD are baby gender, lack of knowledge, social support, and mother role and mother infant attachment.

The baby gender is one of the sources that increased the incidence of occur PPD among mothers with hospitalized infant in NICU, especially if the infant gender is female infant (Mohammad, 2008). According to Jordanian socio-culture the mothers of female infants fear that rumours about their babies' possible disease or deformities may prevent her from getting married in the future (Mohammad, 2008).

Furthermore, lack of knowledge is another source of PPD for mothers with hospitalized infants, whether it is regarding infant health status. Mothers need to know all information regarding to their babies health status, medications, medical interventions, medical diagnosis (Tahirkheli et al, 2014; Mohammad, 2008). The Lack of knowledge among mothers is due to the absence of health education in government Jordanian hospitals. It is often the case that mothers have misconceptions about premature babies or babies admitted to the NICU, mistakenly 
believing that their babies are abnormal or different from other infants (Tahirkheli et al, 2014; Mohammad, 2008). In addition, mothers fears are aggravated by the medical jargon used among health care professionals; they assume the worst about their infants' health status as they do not fully understand the medical terms used (Tahirkheli et al, 2014; Mohammad, 2008). In addition, Mothers with hospitalized infant in NICU experienced lack of social support from husband, family, siblings, relatives and friends. The social support is very important for mothers in this situation because the mothers feel alone in the world; they can't express their feelings to any one that may increase the symptoms of postpartum depression.

Another source of PPD is mother role and mother infant attachment. Mother fear separation from their infants, as well as interruption in the mother-infant relationship. The major problem is that mothers are unable to act their role of breastfeeding, diapering and clothing their babies. Also mothers often cannot touch, carry or hold their babies, as their babies are hospitalized behind a pane of glass in NICU (Tahirkheli et al, 2014; Mohammad, 2008). In the absence of physical contact between mothers and their infants- who have waited for months to kiss and care for feel stressed, guilty, and helpless. It is fundamentally an interruption in the transition to motherhood. Instead of stepping into the role of being loving mother, they are left feeling like outsiders (Tahirkheli et al, 2014; Mohammad, 2008).

Moreover, the results showed that mothers experience shame and stigma from the admission of their infants to the NICU. This result is due to Jordanian socio-culture glorifying perfect infant appearances and finding ways to criticize or judge anything less than perfect. Mothers with hospitalized infants in the NICU have had their hopes dashed. They do not have perfect, normal and healthy babies; furthermore, they need to provide explanations to their relatives and friends. They need to defend themselves from accusations of genetic or hereditary diseases in their families, so that they do not carry the burdens of that stigma for the rest of their lives. In a conclusion, the mothers with hospitalized infant in NICU experience PPD. the PPD mothers experience many manifestations during this situation such as: shock, surprise, crying, Anhedonia and hopelessness and thinking about harming herself or her baby after the admission of their infants to the NICU, Also there are many sources that influence postpartum depression such as baby gender, lack of knowledge, social support, mother role and mother infant attachment and stigma and shame.

\section{Competing Interests Statement}

The authors declare that there are no competing or potential conflicts of interest.

\section{References}

Alaradi, M. I. (2014). Predictors of uncertainty, stress, anxiety, and depressive symptoms of parents of preterm infants in the neonatal intensive care unit. https://ir.library.louisville.edu/cgi/viewcontent.cgi?article=1024\&context=etd

Al Maghaireh, D. F., Abdullah, K. L., Chong, M. C., Chua, Y. P., \& Al Kawafha, M. M. (2017). Stress, Anxiety, Depression and Sleep Disturbance among Jordanian Mothers and Fathers of Infants Admitted to Neonatal Intensive Care Unit: A Preliminary Study. Journal of pediatric nursing, 36, 132-140. https://doi.org/10.1016/j.pedn.2017.06.007

Blencowe, H., Cousens, S., Oestergaard, M. Z., Chou, D., Moller, A.-B., Narwal, R., \& Say, L. (2012). National, regional, and worldwide estimates of preterm birth rates in the year 2010 with time trends since 1990 for selected countries: a systematic analysis and implications. The Lancet, 379(9832), 2162-2172. https://doi.org/10.1016/S0140-6736(12)60820-4

Busse, M., Stromgren, K., Thorngate, L., \& Thomas, K. A. (2013). Parents' responses to stress in the neonatal intensive care unit. Critical Care Nurse, 33(4), 52-59. https://doi.org/10.4037/ccn2013715

Campbell, L. (2018). Children Can Also Suffer When Their Mothers Have Postpartum Depression. Retrieved from : https://www.healthline.com/health-news/children-suffer-when-mothers-have-postpartum-depression.

Davis, L., Edwards, H., Mohay, H., \& Wollin, J. (2003). The impact of very premature birth on the psychological health of mothers. Early human development, 73(1-2), 61-70. https://doi.org/10.1016/S0378-3782(03)00073-2

Dellenmark-Blom, M., \& Wigert, H. (2014). Parents' experiences with neonatal home care following initial care in the neonatal intensive care unit: A phenomenological hermeneutical interview study. Journal of Advanced nursing, 70(3), 575-586. https://doi.org/10.1111/jan.12218

Eapen, V., Dadds, M., Barnett, B., Kohlhoff, J., Khan, F., Radom, N., \& Silove, D. M. (2014). Separation anxiety, attachment and inter-personal representations: disentangling the role of oxytocin in the perinatal period. PLoS 
One, 9(9), e107745. https://doi.org/10.1371/journal.pone.0107745

Flacking, R., Lehtonen, L., Thomson, G., Axelin, A., Ahlqvist, S., Moran, V. H., \& Dykes, F. (2012). Closeness and separation in neonatal intensive care. Acta Paediatrica, 101(10), 1032-1037. https://doi.org/10.1111/j.1651-2227.2012.02787.x

Korja, R. (2009). Early relationship between very preterm infant and mother: The role of infant, maternal and $\begin{array}{lllll}\text { dyadic } & \text { factors. } & \text { May } & 20, & 2015,\end{array}$ http://www.doria.fi/bitstream/handle/10024/47017/AnnalesD870Korja.pdf?

Lefkowitz, D. S., Baxt, C., \& Evans, J. R. (2010). Prevalence and correlates of posttraumatic stress and postpartum depression in parents of infants in the Neonatal Intensive Care Unit (NICU). Journal of clinical psychology in medical settings, 17(3), 230-237. https://doi.org/10.1007/s10880-010-9202-7

Mohammad, K. I. S. (2008). Incidence and factors associated with postnatal depression among Jordanian women. Griffith University.

Razali, N. M., \& Wah, Y. B. (2011). Power comparisons of shapiro-wilk, kolmogorov-smirnov, lilliefors and anderson-darling tests. Journal of statistical modeling and analytics, 2(1), 21-33.

Roy, R. N., Schumm, W. R., \& Britt, S. L. (2014). Transition to parenthood: Springer. Retrieved from https://www.springer.com/gp/book/9781461477679

Shelton, S. L., Meaney-Delman, D. M., Hunter, M., \& Lee, S.-Y. (2014). Depressive symptoms and the relationship of stress, sleep, and well-being among NICU mothers. Journal of Nursing Education and Practice, 4(8), 70-79. https://doi.org/10.5430/jnep.v4n8p70

Sivasubramaniam, P., Quinn, C. E., Blevins, M., Al Hajajra, A., Khuri-Bulos, N., Faouri, S., \& Halasa, N. (2015). Neonatal Outcomes of Infants Admitted to a Large Government Hospital in Amman, Jordan. Global journal of health science, 7(4), 217-234. https://doi.org/10.5539/gjhs.v7n4p217

Tahirkheli, N. N., Cherry, A. S., Tackett, A. P., McCaffree, M. A., \& Gillaspy, S. R. (2014). Postpartum depression on the neonatal intensive care unit: current perspectives. International journal of women's health, 6, 975-979.

UNICEF. (2012). On World Prematurity Day, UN Stresses Benefit of Low-Cost Care in Saving Newborns.

WHO. (2012). Born Too Soon: The Global Action Report on Preterm Birth.

Yurdakul, Z., Akman, I., Kuşçu, M. K., Karabekiroglu, A., Yaylalı, G., Demir, F., \& Özek, E. (2009). Maternal Psychological Problems Associated With Neonatal Intensive Care Admission. International journal of pediatrics. Retrived from file://C:/Users/user/Downloads/591359.pdf

\section{Copyrights}

Copyright for this article is retained by the author(s), with first publication rights granted to the journal.

This is an open-access article distributed under the terms and conditions of the Creative Commons Attribution license (http://creativecommons.org/licenses/by/4.0/). 